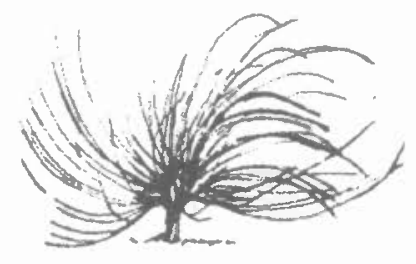

\title{
Vallejo poeta, Vallejo periodista: "dos espíritus” en el mismo escritor
}

\author{
José Alberto Gatgens Céspedes ${ }^{l}$ \\ Universidad de Costa Rica \\ San José, Costa Rica \\ republicaindependiente@gmail.com
}

\section{Resumen}

En este ensayo, el autor analiza dos crónicas periodísticas del gran poeta peruano César Vallejo, con el criterio de que poeta y periodista nunca fueron dos, sino uno solo, sin necesidad de desdoblamientos o encuentros antimateria.

Palabras claves: Escritores modernistas y vanguardistas, crónica, poesía, periodismo, narrativa, desdoblamiento.

\begin{abstract}
In this paper, the author analyzes two news chronicles of the great Peruvian poet César Vallejo under the criterion that poet and reporter were never apart without the need of splitting or anti-mater encounters.
\end{abstract}

Keywords: Modernist and avant-garde writers, chronicle, poetry, news, narrative, splitting.

Recibido: 08 de setiembre, 2010 - Aprobado:29 de junio, 2011

1 Licenciado en Periodismo y estudiante de la maestría en estudios latinoamericanos de la Universidad de Costa Rica. 


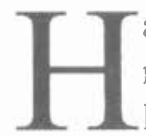

ay un estudio que aún falta por realizar entre los escritores del modernismo y de las vanguardias: uno esotérico que abarque la capacidad de desdoblamiento que tenían esos trabajadores de la palabra, pues, por lo visto, tenían la increíble facultad de no ser la misma persona cuando redactaban sus crónicas periodísticas, que cuando se trenzaban en brava batalla contra las palabras o la rima.

Es posible que ese sea el trabajo que está haciendo falta para que la obra de los grandes poetas del modernismo y de las vanguardias se estudie de una manera más integral. Pero ese estudio tendría que empezar por explicarle a Rubén Darío que en realidad no era él, o al menos era otro él, el que pretendía ser sólo un él cuando decía: "Yo soy aquel que ayer no más decía/ el verso azul y la canción profana".

Pupo-Walker y Shaw tienen razón cuando dicen que hablamos y pensamos mucho en el modernismo, pero nos referimos poco a la prosa de ese movimiento, pues la poesía ha reclamado el sitio de preferencia de la crítica. Crítica que reconoce la importancia del cuento y de la novela, por ejemplo, en el modernismo, pero que se queja de lo poco que se ha hecho y se hace al respecto (Pupo-Walker, 1993; Shaw, 1993). Es decir: nos encontramos ayunos de trabajos que eleven al lugar que se merece la narrativa.

Y si pensamos en el periodismo, la cosa aún es más mezquina. La extensa obra periodística de José Martí, de Darío y de otros está casi olvidada, y pareciera que poco se estudia en las universidades, las que centran su interés por los trabajos poéticos, cuando lo cierto es que "más de la mitad de la obra escrita de José Martí y dos tercios de la de Rubén Darío se componen de textos publicados en periódicos" (Rotker, 2005).

Uso estos acercamientos a la crónica de los modernistas porque creo que son los mismos que atañen a la crónica de los vanguardistas. Es decir, que hay un grande y valioso estudio de la poesía, pero relativamente poco acerca de la prosa y menos aún de sus trabajos periodísticos.

Para Susana Rotker (2005, pág. 25), quien investigó de manera acuciosa el nacimiento de la crónica (que más adelante los norteamericanos bautizaron como New Journalism) "no necesariamente hay rupturas cortantes entre las obras "puras" (léase poesía) y las mixtas (léase crónicas) de un mismo autor". 
En el caso específico de César Vallejo, para Froilán Escobar y Ernesto Rivera (2008, pág. 20), "el Vallejo que escribe sus crónicas desde Europa no deja nunca de ser el Vallejo de Trilce o de España, aparta de mi ese cáliz. Al igual que el caso de Dario, Martí y Gutiérrez Nájera, el poeta y el periodista no se separan".

De la misma forma que la poesía y la narrativa de ficción (hago la aclaración porque existe la novela sin ficción), las crónicas periodísticas mantienen su vigencia e importancia por su lenguaje y estructura, más que por el suceso o hecho de referencia, ya que ese acontecimiento tiene poca "importancia periodística" en este momento, docenas y docenas de años después de que ocurrieron. Acerca de las líneas anteriores, Susana Rotker, refiriéndose a los modernistas, dice que:

"Muchas de las crónicas modernistas, al desprender de ambos elementos temporales (tema y referencialidad) han seguido teniendo valor como objetos textuales en sí mismos. Es decir que, perdida con los años la significación principal que las crónicas pudieron tener para el público lector de aquel entonces, son discursos literarios por excelencia" (Rotker, 2005, pág. 131).

Lejos entonces de perder su valor por alejarse temporalmente del suceso que sirvió de pretexto para que se crearan, muchas de las crónicas periodísticas de esos grandes poetas mantienen su vigencia por su lenguaje, que suele ser el mismo de los poemas, encontrándonos ante una "prosa poética periodística", rica, variada y en gran forma, esperando por ser estudiada, descubierta y redescubierta.

Como señalaba unos cuantos párrafos atrás, citando a Escobar y a Rivera, no hay diferencia entre el Vallejo de Trilce y el Vallejo que se fue a vivir a París, por lo tanto, la hipótesis a plantear es que en sus crónicas se tendrán que encontrar en uno solo el Vallejo poeta con el Vallejo periodista. Hipotéticamente hablando, sería como juntar a los dobles antimateria, que si se llegaran a tocar podrían producir una paradoja en el espacio-tiempo, acabando con el universo entero... Pero eso sería mucho decir, sería más que la hipótesis esotérica del desdoblamiento.

Por lo tanto, en las siguientes páginas se trabajarán dos crónicas periodísticas del gran César Vallejo, con el criterio de que poeta y periodista nunca fueron dos, sino uno solo, sin necesidad de desdoblamientos $o$ encuentros antimateria. 


\section{Vallejo: el poeta periodista}

La obra poética de Vallejo es harto conocida, comentada, criticada y admirada. Desde sus Heraldos negros (escrito en 1918 y publicado en 1919), pasando por Trilce (1922) y hasta España, aparta de mi ese cáliz (1939), a casi ya cien años de sus primeras publicaciones, su trabajo despierta cada día más admiración, lectura y producción crítica. Sin embargo, como se comentaba antes, su producción periodística está un poco olvidada.

Según Carrasco Santaya:

"Este descuido o desinterés por el pensamiento vallejiano, que no sea el poético, quizá se deba, en parte, a la poca difusión que se le ha dado a sus textos en prosa, y dentro de ellos, específicamente los relacionados a sus reflexiones teóricas. Nos estamos refiriendo por supuesto a ensayos, artículos, crónicas, reportajes, correspondencia, entre otros. Existen solo contadas ediciones, con tiraje reducido; además, ya publicadas hace años, que hacen dificil el poder realizar investigaciones exhaustivas y minuciosas. No existe, por ejemplo, un Archivo Vallejo, donde se brinden las mejores oportunidades para estudiar su obra". (Santaya, 2005, pág. 43)

Sin embargo, hay que tener claro que la inclinación periodística del poeta peruano más bien fue una faceta siempre presente. Antonio González Montes (2002), en su libro Escalas, hacia la modernización, resume que "Vallejo se vinculó con el periodismo desde muy temprano, primero, publicando sus poemas en diarios y revistas de la época, y después, enviando artículos y comentarios sobre diferentes tópicos o personajes de la cultura peruana".

Con el periodismo, Vallejo algo habrá aliviado sus penurias económicas, porque, citando un verso de sus poemas humanos, con "la cantidad enorme de dinero que cuesta el ser pobre", mucho debió padecer por ese dinero. Tanto es así, que en la mitad de la década del veinte recibe una beca para ir a España, pero luego renuncia a ella por sentirse moralmente afectado. Le dirá a su amigo Pablo Avril de Vivero: "Tengo 34 años y me avergüenza vivir todavía becado" (Rodriguez Ortiz, 1996, pág. 10), lo que muestra una fuerte ética y moral del peruano, pero también su precariedad monetaria. 
González Montes (2002, pág. 43) hace notar que su producción periodística en Europa (1923-1928) es más vasta que la realizada en América, supongo que debido a la necesidad de procurarse los ingresos económicos necesarios para la supervivencia, aunque aclara que lo escrito en Perú también es importante.

Este breve ensayo pretende acercase a dos textos periodísticos que Vallejo realizó ya en París. Son dos hermosos textos con varias diferencias entre sí. Uno de ellos: Los funerales de Isadora Ducan, me llamó mucho la atención porque se trata de la famosísima bailarina estadounidense de fin del XIX y principios del XX, Isadora Duncan, quien terminó sus días en París; pero me llama la atención porque existe otra crónica del modernista Enrique Gómez Carrillo que trata de la visita que realizó la bailarina a Roma, esa crónica lleva el nombre de La bacante que baila. Denota esta simple conexión la importancia del personaje en el que se centra la crónica de Vallejo.

La otra crónica periodística que exploraré lleva por título Un extraño proceso criminal. Sí, se trata de la cobertura que hace Vallejo al asesinato de una mujer en manos de su amante. Pero el aporte vallejiano va más allá de la simple gacetilla color carmín. En este caso, Vallejo no solo saca a relucir su lenguaje, sino que también analiza, comenta y creo que incluso hace gala de fino humor, además de explorar los límites delgados y borrosos entre ficción y realidad.

\section{Los funerales de Isadora Duncan}

Apareció este trabajo en Mundial, número 385, Lima, el 28 de octubre de 1927. En él, Vallejo narra los funerales de Isadora Duncan, quien nació en San Francisco, California y murió en París. Se trata de una crónica más bien breve, pero con una enorme fuerza sintetizadora, donde se comprende la tragedia de la vida de la artista y la enormidad de sus pasos danzantes.

Tanto esta crónica como Un extraño proceso criminal, tienden más bien hacia el resumen en lugar de las escenas, se destaca particularmente el uso del lenguaje y algunos importantes recursos literarios, propios de Vallejo.

La crónica empieza por situar al lector en el momento mismo en que la pira funeraria está acabando con el cuerpo material de la bailarina, al mismo tiempo en que miles de soldados desfilan por el Arco del 
Triunfo, ajenos a la pérdida de una de las más grandes artistas de esas épocas. La muerte llega a todos y el mundo no se detiene, pareciera decirnos este inicio:

\begin{abstract}
"A esta hora están quemando en el Columbarium de París un cuerpo natural. Mientras cuarenta mil unidades de la Legión Americana, desfilan del Arco del Triunfo al Hotel de Ville, están a esa hora quemando en el cementerio del Pére Lachaise, las últimas falanges y los postreros carpos del cuerpo, mediano y regular, de Isadora Dunca".
\end{abstract}

Rescato algo que me llama la atención de esta crónica: la atemporalidad a la que recurre. $Y$ no me refiero a que su calidad estética hace que nos olvidemos del hecho lejano, periodísticamente hablando, sino a que cuando el poeta dice "a esta hora", en realidad, la posibilidad imaginativa que produce la literatura recrea el hecho de nuevo y una vez más, Isadora Duncan vuelve a consumirse entre las llamas. No podría afirmar que esa haya sido la intención del autor (cosa que no me interesa saber, tampoco), pero el texto sí me lo sugiere, porque además el autor insiste en eso, lo utiliza como anáfora para hacernos notar el momento del fuego.

En ese mismo largo párrafo primero, Vallejo insiste en la antítesis literaria, antítesis de vida y muerte:

"Suenan por el anverso de la vida, del lado de los cow boys, vencedores de Verdun, bombos de primera y tibias bárbaras y resuenan, por el reverso de la vida, del lado de la artista caída, las sinfonías de Chopín y de Beetovhen".

Además de esa confrontación de realidades, metaforiza la muerte de la bailarina al decir "la artista caída", como un anticipo al campo de batalla que fue su vida trágica.

Y es que ni aún la muerte le da espacio a que Isadora deje de bailar, para Vallejo "la bailarina de los pies descalzos", como suele llamarla, muerta sigue en lo suyo:

"La orquesta de Valvé está a esta hora acompañando al cuerpo de la mujer más rítmica del mundo a danzar, entre llamas verdaderas, 
el número más rojo y más cordial de las esferas. Raf Lawton ejecuta luego el Concierto en Re de Bach...".

Vallejo insiste en recalcar el tipo de funeral ante el que se está, que no es un funeral cualquiera, sino ante el de un ser fantástico, casi divino, donde los opuestos - castos y sonrosados; castos y dionisiacosson posibles, son un oxímoron:

"Son los funerales, castos y sonrosados, de Isadora Ducan. La pira griega recibe alegremente un leño antiguo, familiar por la estatura, rico en esencias combustibles. Son los funerales, castos y dionisiacos, de Isadora Duncan".

Acto seguido, Vallejo poeta nos recuerda a los lectores la fugacidad de la vida humana, lo poco que dura el tiempo del hombre, que la muerte horizontaliza incluso a los más célebres y divinos de los seres humanos, que esa muerte también será la nuestra, porque estamos hechos de la misma materia, humana y regular que Isadora, materia producto del universo, nunca de algún dios:

"Al resplandor del fuego en que ahora está ardiendo el cuerpo, humano y regular, de Isadora Ducan, vemos con nuestros ojos, humanos, regulares, que es carne y nada más cuanto ha sido la bailarina de los pies desnudos. Ni figura de los vasos griegos ni estatua de Tanagra. Ni velos ni arabescos. Tampoco bajorrelieve antiguo ni la musa que juega a los huesecillos, sobre los arenales de Salamina. La bailarina de los pies desnudos fue solo carne viva, acto caminante y orgánico del universo. ¿A qué más sino a carne puede aspirar el ritmo universal?"

Unas cuantas líneas más abajo, gracias a las constantes repeticiones, Vallejo reitera quién era la difunta, un ser fantástico que elevó los sentidos a nuevos niveles de deseo y pasión:

"Y en Isadora Duncan fue ir carne más carne, el hueso más hueso, el dolor más dolor, la alegría más alegre, la célula más dramática: todo para violentar la inquietud del ser humano y para hacer la vorágine vital más dionisiaca". 
El peruano recurre, a continuación, al testimonio de otras personas para contar la tragedia de la más grande bailarina de esas épocas. Parece que es un caso donde el extraordinario arte se suma a una tragedia inmensa: "Isadora Duncan fue la bailarina más grande de la época y la mujer más trágica de todas las mujeres".

Más adelante, utilizando las palabras de Fernand Divoire cuenta de manera breve la causa de parte de su tragedia:

"(...) había visto quebrarse de un solo golpe todas las fuerzas de su vida, el día que un automóvil cayó en el Sena, ahogando a sus tiernos hijos, Patrick y Deardree. Desde aquel día, la vida de la Gran Bailarina no fue más que un suicidio largo, voluntario y tenaz...".

Isadora Duncan fue una bailarina que gustaba de los movimientos naturales inspirados por el viento y las olas, más que los conceptos academicistas del baile, sentía honda pasión por el mundo griego, y en parte por eso, Vallejo hace un continuo recordatorio de ese pasado que a la Duncan le gustaba recobrar. Vallejo logra una síntesis con las palabras precisas, además de bellas:

'Norteamericana de San Francisco, penetró en el espíritu dionisiaco de la danza pagana, bailando al pie del mismo Acrópolis. Al presentarse, en la primera vez en París, en 1903, predicó toda su estética en estas breves palabras: 'Lo que es contrario a la naturaleza no es bello"".

Más adelante, en la crónica, Vallejo recuerda que ella fue quien bailó lo que antes era impensable, como sinfonías de Beethoven, de Brahms y Chopin, además de otras piezas de Wagner. Testigo de excepción de su deteriorada vida fue el propio peruano, quien vio su última presentación y presentía ya la cercanía del fin de la bailarina: "Yo la vi en su último recital del Teatro Mogador, en julio de este año, bailar -con ya moribundo brillo- la Sinfonía Inacabada de Schubert y Tannhauer".

La crónica, más que una nota fúnebre del momento en que ella "baila con el fuego de verdad", consta de una estética cercana a la descripción de una pieza de ballet. Según Orrillo (1998, pág. 33), Vallejo tenía un gusto especial por la danza (además del cine), lo que 
se evidencia en varias crónicas, especialmente en la crónica que acá traigo a detalle.

Los detalles trágicos llegan con la suavidad de quien sabe escoger las palabras, y son apenas claves que permiten entender lo que sucedió. Un final trágico, como de película:

"Murió ahorcada por un velo, recorriendo en automóvil y a ciento veinte caballos de fuerza, la luminosa Costa Azul, una tarde de estío de 1927. Su cuerpo, envuelto en una túnica violeta, fue quemado en El Columbarium de París, entre lises, rojas y margaritas y a los sones de un coro de canéforas. Biografia como se ve, digna de una tragedia de Esquilo".

Al final, Vallejo cierra con una manera más que poética: la bailarina recibe un adiós digno de su porte, etéreo y divino:

"Isadora Duncan acaba, de este modo, en un poco de humo ligero y otro poco de ceniza. Pero la tierra retiene para siempre el latido de sus pies desnudos, que ritman el latido de su corazón".

Ese no es el fin de una mujer o de un hombre cualquiera, es el fin, suave y delicado de una diosa, para quien la tierra retendrá el latido de sus pies desnudos. La crónica es una puesta en escena del funeral de la "bailarina de los pies descalzos".

\section{Un extraño proceso criminal}

La crónica de marras trata del asesinato que comete un hombre de negocios a su novia o amante. Vallejo, salvando las distancias, realiza una "crónica policial" que en sus dedos se convierte en un documento de análisis de lo que hacen la policía y los medios de comunicación que siguen el suceso, pero que, además del fino humor que se asoma entre las líneas, hay un adelanto de lo que Garcia Márquez y Tomás Eloy Martínez harian varias décadas más adelante: hay una distorsión entre la realidad y la ficción.

Según Orrillo (1998, pág. 34), la crónica de Vallejo es más bien como un pretexto para poder "develar algunas de las miserias de la sociedad en la que le ha tocado vivir...". 
En un punto la crónica parece más bien un cuento, parece una gran ficción. Y esto, lejos de quitarle valor al documento, más bien le aporta. Y le aporta tanto que considero que ese solo punto hace que Un extraño proceso criminal se lea como un texto innovador, y que aún a ocho décadas y pico de su publicación sigamos disfrutando de él.

Aquí, creo que se puede aplicar una consideración que hace Cristine Mattos en el prólogo titulado Una poética de la incertidumbre para el libro La otra realidad (selección de textos de Tomás Eloy Martínez):

"La ambigüedad entre lo real y lo ficticio produce consecuencias diversas y profundas. Entre ellas, quizá la más determinante sea la renuncia a la necesidad de establecer límites fijos entre una perspectiva subjetiva y objetiva, desdibujando así las jerarquías de relación entre el Yo y el Otro, y todo lo que a ellas se conecta: el autor y el lector, el hombre y su obra, o -como definió Umberto Eco- el autor explícito y el implícito". (Mattos, 2006, pág. 9)

Para Orrillo (1998, pág. 34), Vallejo “desmitifica el sórdido papel que cumple el periodismo amarillo". Sin duda que sí, porque los argumentos anteriores, más la belleza del lenguaje, lo certero de sus observaciones y el fino sentido del humor que hay en el trabajo, dan a esa crónica judicial, de sucesos, o policial, o como se quiera llamar, la dimensión de una excelente pieza de literatura. De hecho, el poeta peruano dedicó más de una crónica al mismo caso, lo que me demuestra la acuciosidad con que Vallejo se tomaba su trabajo.

En Un extraño proceso criminal se pueden encontrar varias de las herramientas usadas por los escritores, tanto los modernistas como los subsecuentes, que señalan Escobar y Rivera:

"Es decir, para lograr esta nueva síntesis genérica, se violentó la estructura clásica informativa con la introducción de historias de personajes, diálofos, comentarios, analogías, juegos de oposiciones, saltos cronológicos, suspenso, visiones múltiples, proposiciones yuxtapuestas, metáforas y otras figuras literarias que, sin desviertuar el suceso referencial, permitían la intensificación de la emoción con el fin primordial de conmover al lector" (Froilán Escobar y Ernesto Rivera, 2008, pág. 15). 
Las cita anterior nos da algunas pistas del por qué la crónica puede ser leída hoy sin que haya pérdida de interés en el relato. La crónica da inicio con una descripción del asesino. Dice que el sujeto se parece un poco a esos dibujos "lordbyreanos". Contextualiza el suceso dentro del mundo artístico. Habla de sus particulares características fisicas, de su ojo a lo Judas Iscariote.

En el segundo párrafo, Vallejo adelanta el desenlace de la crónica al comentar que ese hombre, Guyot, "dentro de pocos días va a ser guillotinado".

Continúa con la descripción, lo identifica como un "bravo jugador de millones en la bolsa y en extremo tenorio, es, en síntesis, un hombre trascendental".

Y se vuelve trascendental cuando, luego del crimen, "ocho días anduvo después paseándose en París, muy orondo, sin que la policía pudiese dar con él". A partir de ahí el poeta nos va dando pinceladas de crítica a la policía, de cómo la prensa cubría el asunto, junto con piscas de humor:

"La policía no podía encontrarle, justamente, porque él no se había escondido. Conocimiento tan agudo y sorprendente, como éste que Guyot mostraba de la sicología policial, le valió aparte de una libertad de ocho días, el que su caso adquiriese un brillo insólito y el que tuviera, en los primeros días de su pesquisa, buena prensa".

Vallejo echa mano de un famoso criminalista de la época, Henri Robert, para constatar que "la mejor manera de huir de la policía consiste en no ocultarse de ella".

El criminal, no solo seguía libre, sino que empezó correspondencia con la policía:

"Guyot entraba y salía de su casa, almorzaba con amigos en los grandes boulevares, asistía cotidianamente a las sesiones de la Bolsa, iba al teatro, se bañaba y la policía seguía ignorando totalmente sus trazas y su pista. Todavía más. La audacia de Guyot le llevó a iniciar y sostener una nutrida correspondencia con la policía de París". 
Sin duda, Vallejo está haciendo escarnio de la incapacidad de la policía. Más adelante sentenciará:

"Pero, de todos modos, el precedente quedaba sentado de que para no caer en manos de la policía, no hay que ocultarse de ella ni de nadie. Tal era el aporte de Guyot a la sicología policial".

Llegado el momento del juicio, Guyot traza un plan: aparentar ser inocente a toda costa. Al entrar a la sala, el cronista sigue con atención lo que hace el indiciado y cuenta como con "su ojo sano ha trazado, al entrar a la sala, diez paralelos en torno suyo"; y cita desde los jueces hasta las elegantes damas de la sociedad parisiense que llegan a presenciar el juicio. El párrafo no solo sirve para narrar el juicio, también funciona como una breve descripción de la sociedad parisiense, específicamente hacia las señoras que tiene el dinero (y por consecuencia el tiempo) para presenciar el juicio, sin embargo, el detalle es tan sutil que puede, casi está a punto, de pasar inadvertido.

"Fueron diez vistazos generales, plenos de confianza que parecía cinismo y de aplomo que, parecía inconciencia". La frase sirve como antecedente al derrumbe del homicida en su teatro jurídico, de su derrumbe como ser humano y del momento en que la crónica transita hacia su punto más elevado, el momento en que queda la duda de si es realidad o si es un artificio del periodista:

"Mas cuando se inició el interrogatorio, Guyot dio su primera respuesta dirigiendo una larga mirada sobre los miembros del Tribunal. Uno de éstos, el sustituto Mhilad, tenía un parecido asombroso con Guyot. La misma edad, el mismo ojo derecho mutilado, el corte y color del bigote, la línea y espesor del busto, la forma de la cabeza, el peinado. " $¡ U n$ doble absolutamente extraordinario!" -comenta L'Oeuvre. El procesado vio a su doble y algo debió cambiar en su reino interior..." PÁG 100

Ahí, el sujeto se desarma por completo, su plan se trunca. Al encontrarse con su doble, con él mismo, el juicio se vuelve una parajoda para Guyot, su universo está a punto de estallar: 
"Le Figaro opina que la presencia de su doble empezaba a causar un visible y misterioso malestar, un gran miedo tal vez. A partir de ese momento, siempre que se formulaba a Guyot una pregunta grave y tremenda, miraba con su único ojo sano a su doble y respondía cada vez más vencido. La presencia de Mhilad le hacía, sin duda, un daño creciente, influyendo funestamente en la marcha de su espíritu. Al final de la primera audiencia, Guyot sacó su pañuelo y se puso a llorar".

El poeta peruano, con enorme poder de síntesis, revolcando en el espíritu del asesino, jugando con los sentidos entre realidad y ficción, también logra citar a uno de los medios de comunicación más importantes, que al igual que él, le dan seguimiento al caso.

La crónica continúa con el abatimiento final de Guyot, de cómo a medida que fue avanzando el juicio se fue consumiendo más y más, hasta el punto en que: "Al leerse el veredicto de muerte, Guyot estuvo hundido en su banco, la cabeza sumersa entre las manos, insensible, frío, como una estatua". Al parecer, sólo una cosa le importaba ya al condenado a la navaja: "Guyot solo miraba fijamente a la cara de Mhilad, su doble, el sustituto del Presidente del Tribunal".

Vallejo lanza algunas líneas acerca del doble, pero lejos de esclarecer el asunto, si se trata de una persona verdadera o de si solo es un "recurso literario", más bien quedan más dudas que certezas. Periodísticamente es inusitado, literariamente es muy bueno:

"Existe, a veces, al lado del criminal, otro hombre, su doble, que está en el secreto de la conducta y de la conciencia del acusado. Cuando este doble está presente, su presencia es conminatoria, tácita e ineludible, para que el acusado diga la verdad. El doble juega entonces el múltiple rol de un juez severo, de un testigo temible, de un acusador implacable. Guyot es, en síntesis, un hombre trascendental".

$\mathrm{Y}$ es un hombre trascendental, capaz de invocar en un juicio a un doble exacto de él, para que, enfrentado con él mismo en el espejo tenga que derrumbarse. Ocupa de verse, de mirarse para que su conciencia tome conciencia de sus actos, de su juego, de su burla y de su intento de salirse con la suya: toma plena conciencia de sus actos. Y ya no podrá 
levantarse, porque cada vez se hunde más al verse en el espejo, que es su doble, del lado de la justicia, pero que al mismo tiempo es él mismo.

El texto, visto de manera anacrónica, parece borgiano; solo que escrito por Vallejo y adelantado a Borges.

\section{Conclusiones:}

Creo que, como lo señalé antes, estamos ante un adelanto de lo que luego vendría en América Latina: un García Márquez contando la realidad como si fuera una gran ficción, un Tomás Eloy Martínez desdibujando la frontera entre ficción y realidad. Pero eso es tema de otro ensayo.

La crónica de Vallejo es un trabajo bello, meticuloso, donde se encuentra, me parece, la urgencia de la crónica rápida, pero bien hecha. Hay una estructura muy bien lograda, donde se escucha la mano cuidadosa del poeta, de ese ser humano que conoce su oficio y que, a pesar de la urgencia del día a día, logra sacar de la vida cotidiana páginas de prosa poética. A esto es a lo que se refiere Orrillo (1998, pág. 105) cuando afirma que Vallejo trasciende los géneros como el periodismo y la literatura, donde el primero es lo utilitario y pragmático y lo segundo es "lo intemporal, lo puro, lo no utilitario"

El periodismo le habrá ayudado a Vallejo a sobrevivir, lo mismo que le permitió a Martí y Dario aliviar en algo sus penas pecuniarias; les habrá ayudado a sobrevivir. ¿Cuánto le habrá servido a Vallejo su trabajo cotidiano para sus trabajos poéticos? Eso no lo sabemos, pero lo que sí sabemos es que encontramos un continuador (y latinoamericano), del camino que empezaron a recorrer los modernistas (Rotker, 2005); un sendero que inició Martí y luego se bifurcó hacia otras partes del mundo; que caminando alcanzó a Darío, Gutiérrez Nájera, Gómez Carrillo y lo continuó César Vallejo. Y a él lo continuarían otros más. A él lo continuarán muchos más.

Así, sin necesidades de secretos rituales, el poeta y el periodista se juntan en uno, uno que recorre los temas con gran maestría, que es más que un gacetillero o un cronista de sucesos. Vallejo tiene la capacidad de brindar comentarios y análisis como los que hace de la prensa en Un extraño proceso criminal; de ver la complejidad del mundo cuando en Los funerales de Isadora Duncan los soldados marchan, indicando que la vida sigue hacia adelante, a pesar de que acaba de morir una deidad. 
Vallejo, fiel a la forma que adoptaría la crónica en América Latina, enfoca su máquina de escribir a la persona, no al suceso. Y eso, aunque es algo que ya habían hecho los modernistas, sigue teniendo un enorme valor, pues hay humanidad en la noticia que se transmite. No se trata de un hecho, se trata de lo que le pasa a alguien. Y ahí está la delgada línea divisora entre ficción y realidad: al enfocar lo personal se deja de lado lo general: el hecho, y se escribe, se mira, se lee desde una perspectiva más particular, tratando de comprender al ser humano al que le suceden las cosas que le suceden. Y para comprender a ese ser humano es posible que se requiera, a veces, de mucha imaginación para tratar de explicar las razones que tiene un hombre para actuar de tal o cual manera, porque la realidad es caleidoscópica y es insuficiente con una sola versión "absoluta" del hecho para brindar las implicaciones, como lo pretende el periodismo informativo.

Sí, sin duda se puede requerir de mucha imaginación para hacer una buena crónica periodística en profundidad; pero no tanta como para dudar que el periodista y el poeta siempre fueron uno solo.

\section{Referencias}

Froilán Escobar y Emesto Rivera, e. (2008). Crónicas latinoamericanas: periodismo al limite. San José: Fundación Educativa San Judas Tadeo.

Mattos, C. E. (2006). La otra realidad. Buenos Aires: Fondo Cultura Económica de Argentina, S.A.

Montes, A. G. (2002). Escalas, hacia la modernización. Lima: Fondo Editorial de la UNMSM.

Orrillo, W. (1998). César Vallejo: periodista paradigmático. Lima: Fondo Editorial Universidad Nacional Mayor de San Marcos.

Oscar Rodríguez Ortiz, c. (1996). César Vallejo, crónicas de poeta. Venezuela: Biblioteca Ayacucho.

Pupo-Walker, E. (1993). El cuento modernista: su evolución y características. En L. I. Editor,

Historia de la literatura hispanoamericana (págs. 515-522). Madrid: Cátedra.

Rotker, S. (2005). La invención de la crónica. Ciudad de México: Fondo Cultura Económica, Fundación para un Nuevo Periodismo Iberoamericano.

Santaya, L. A. (2005). Cybertesis. Recuperado el 30 de junio de 2010, de http://www.cybertesis.edu.pe/sisbib/2005/carrasco sl/pdf/carrasco sl.pdf

Shaw, D. (1993). La novela modernista. En e. Luis Iñigo Madrigal, Historia de la literatura hispanoamericana (págs. 507-513). Madrid: Cátedra. 